\title{
Effect of Guide Nozzle Shape on the Performance Improvement of a Very Low Head Cross Flow Turbine
}

\author{
Zhenmu Chen ${ }^{*}$ Patrick Mark Singh ${ }^{*}$ Young-Do Choi ${ }^{* * \dagger}$ \\ Key Words : Very low head cross flow turbine(초저낙차 횡류수차), Open ducted water channel(개방형 덕트 수로), Guide nozzle \\ shape(가이드 노즐 형상), Guide nozzle radius(가이드 노즐 반경), Guide nozzle angle(가이드 노즐 각도), Performance \\ improvement (성능개선)
}

\begin{abstract}
The cross flow turbine attracts more and more attention for its relatively wide operating range and simple structure. In this study, a novel type of micro cross flow turbine is developed for application to a step in an irrigational channel. The head of the turbine is only $H=4.3 \mathrm{~m}$ and the turbine inlet channel is open ducted type, which has barely been studied. The efficiency of the turbine with inlet open duct channel is relatively low. Therefore, a guide nozzle on the turbine inlet is attached to improve the performance of the turbine. The guide nozzle shapes are investigated to find the best shape for the turbine. The guide nozzle plays an important role on directing flow at the runner entry, and it also decreases the negative torque loss by reducing the pressure difference in Region 1 . There is $12.5 \%$ of efficiency improvement by attaching a well shaped guide nozzle on the turbine inlet.
\end{abstract}

\section{Introduction}

The cross flow turbine is a classic design, and it is invented by Australian Anthony Michell et. al.[1]. Recently, the cross flow turbine attracts more and more attention, because of its relatively wide operating range and simple structure. The traditional cross flow turbine consists of the closed inlet water channel and guide vane, which makes the structure more complex and also increases manufacturing cost. However, for the remote rural region, there are needs for a more simple structure and very low head cross flow turbine. In addition, as the cross flow turbine is applied in the rural area, there are some material of sediment such as the sand, pebble and mud from upstream flowing into the runner passage. These materials cause the turbine to breakdown and shorten the lifespan. Therefore, in this study, a new type of micro cross flow turbine is developed. Unlike the conventional turbine that needs a larger reservoir, which causes harm to the environment, the cross flow turbine with open duct inlet channel is suitable for a step in an irrigational channel. The new type of cross flow turbine without guide vane, but with inlet open duct makes the structure simpler for the rural areas. This kind of turbine should also be protected from the material of sediment being sucked into the runner passage.

However, the turbine with open inlet channel (free flow inlet) and low head shows relatively low efficiency. In order to increase the efficiency of cross flow turbine, a guide was introduced to improve the

\footnotetext{
* Graduate School, Department of Mechanical Engineering, Mokpo National University

** Department of Mechanical Engineering, Institute of New and Renewable Energy Technology Research, Mokpo National University

$\dagger \quad$ 교신저자(Corresponding Author), E-mail : ydchoi@mokpo.ac.kr
} 
performance of turbine[2-7]. Another new method to improve performance of the traditional cross flow turbine is by supplying air into the chamber to suppress the negative torque[8, 9]. Nevertheless, for the new type of cross flow turbine with inlet open duct, a guide nozzle is attached at the turbine inlet to improve the performance. There are two processes to optimize the shape of the guide nozzle. Firstly, by changing the turbine nozzle opening along with changing the guide nozzle radius to investigate the performance and internal flow of turbine. Secondly, keeping the turbine guide nozzle radius at the maximum efficiency achieved in the first process, and the guide nozzle length is changed to improve the performance.

\section{Cross Flow Turbine Model and Numerical Methods}

\subsection{Cross Flow Turbine Model}

Figure 1 shows the schematic view of the new type of very low head cross flow turbine model. The

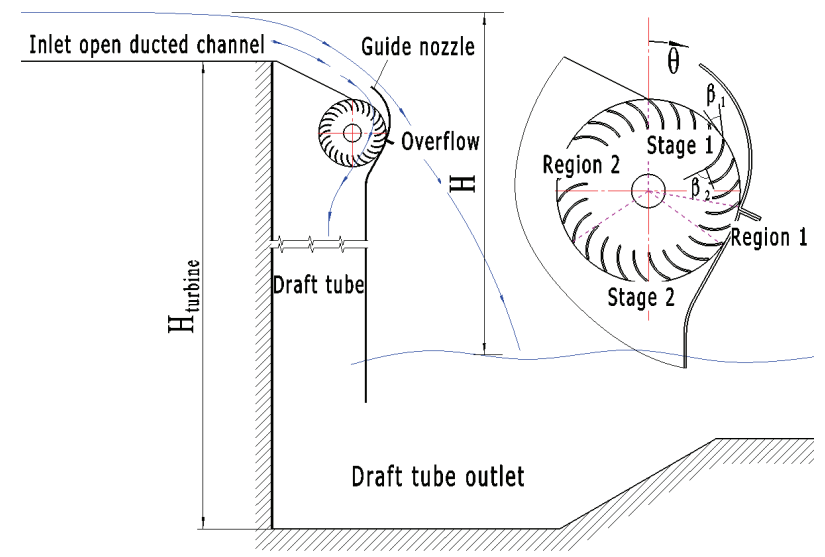

Fig. 1 Schematic view of the very low head cross flow turbine

Table 1 Design parameters of turbine

\begin{tabular}{|c|c|c|}
\hline Item & Nomenclature [Unit] & Value \\
\hline Turbine heigh & $H_{\text {turbine }}[\mathrm{m}]$ & 5 \\
\hline Head & $H[\mathrm{~m}]$ & 4.3 \\
\hline Blade number & $Z$ & 26 \\
\hline Runner diameter & $D[\mathrm{~mm}]$ & 372 \\
\hline Blade inlet angle & $\beta_{1}\left[{ }^{\circ}\right]$ & 33 \\
\hline Blade outlet angle & $\beta_{2}\left[^{\circ}\right]$ & 83 \\
\hline Turbine width & $b[\mathrm{~mm}]$ & 300 \\
\hline
\end{tabular}

structure of the turbine consists of an open ducted water channel, runner and draft tube, without guide vane and nozzle. The draft tube is included in the turbine to reduce the pressure at the top of the draft tube, thereby sucking water into the turbine chamber. The water flow from open water channel separates into two flows: one part of the water flows into the draft tube through the runner passage, and the other overflows down the river with some materials of sediment, preventing damage to the runner structure.

The design point of the present test turbine for the effective head is $H=4.3 \mathrm{~m}$, which is very low in contrast to other typical cases of cross flow turbine's head. More details for design parameters are shown in Table 1.

To improve the performance of turbine, a guide nozzle is attached at the inlet of turbine as shown in

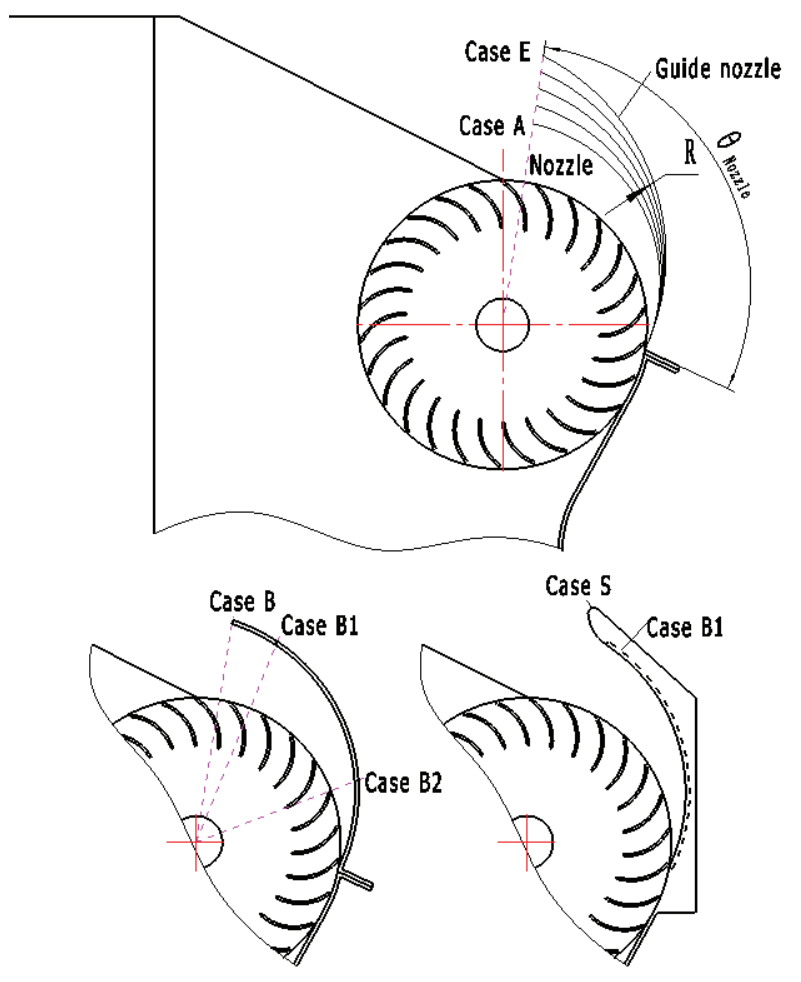

Fig. 2 Variation of the turbine models with guide nozzle

Table 2 Cases of the different turbine guide nozzle radius

\begin{tabular}{|c|c|c|}
\hline Cases & $\begin{array}{c}\text { Nozzle angle } \\
\theta_{\text {Nozzle }}\left[{ }^{\circ}\right]\end{array}$ & $\begin{array}{c}\text { Radius of guide nozzle } R \\
{[\mathrm{~mm}]}\end{array}$ \\
\hline Case A & 107 & 208 \\
\hline Case B & 107 & 228 \\
\hline Case C & 107 & 248 \\
\hline Case D & 107 & 268 \\
\hline Case E & 107 & 288 \\
\hline
\end{tabular}


Fig. 2. Table 2 shows more detail parameters of the different turbine guide nozzle radius. To investigate the effect of the guide nozzle radius on the performance, a series of cases were studied from Cases A to E, with nozzle opening increasing as radius of guide nozzle increases. To further improve the turbine performance, the case (Case B) with maximum efficiency is selected for the second step. In this process, the radius is kept constant and the nozzle angle $\left(\theta_{\text {Nozzle }}\right)$ is changed to investigate the effect of guide nozzle length on the turbine performance as shown in Fig. 2 and Table 3. Case $\mathrm{S}$ has the same radius $(R)$ and nozzle angle $(\theta$ Nozzle) with Case B1. The only difference is that the guide nozzle shape for Case $\mathrm{S}$ has been modified by making a smoother inlet as seen in Fig. 2. The outside guide nozzle shape is simplified for better modeling and mesh quality. The outside guide nozzle shape has no influence on the performance of the turbine.

\subsection{Numerical Methods}

Computational Fluid Dynamic (CFD) analysis is a very useful tool for predicting hydraulic machinery performance at various operating conditions[10]. In this study, a commercial CFD code of ANSYS CFX [11] is employed as a solver. The numerical grids are made in two dimensional geometry in order to shorten the calculation time. Gravity is included for two phase transient calculation and $S S T$ turbulence model is adopted. The grid constitutes greater than $4.5 \times 10^{5}$ elements for the whole flow field. The boundary condition of normal speed is set for the water flow at the inlet and outlet, and the velocity of $0 \mathrm{~m} / \mathrm{s}$ is set for the air flow. The boundary condition of opening is set at the open duct and down river domain. The boundary conditionals are shown in Table 4 .

Figure 3 shows the fine hexahedral numerical grids of the flow field including cross flow turbine model. The area of the runner passage can be divided into four regions by the flow patterns in the runner passage as shown in Fig. 1. Stage 1 gives first output power and Stage 2 gives second output power. However, Regions 1 and 2 consume output power by hydraulic loss.

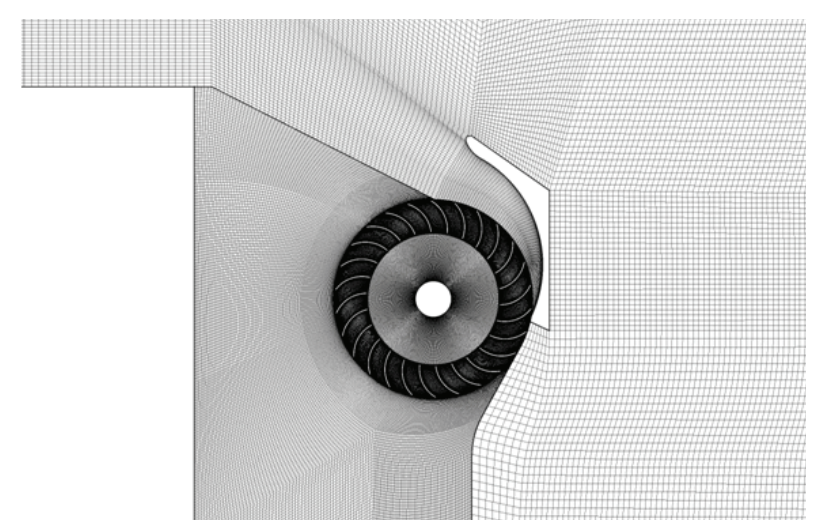

Fig. 3 Fine hexahedral numerical grids of the flow field (Case S)

Table 3 Cases of the different guide nozzle angle Q Q Nozzle

\begin{tabular}{|c|c|c|}
\hline Cases & $\begin{array}{c}\text { Nozzle angle } \\
\theta_{\text {Nozzle }}\left[^{\circ}\right]\end{array}$ & $\begin{array}{c}\text { Radius of guide nozzle } \\
R[\mathrm{~mm}]\end{array}$ \\
\hline Case B1 & 93 & 228 \\
\hline Case B2 & 46 & 228 \\
\hline Case B3 & 0 (Without nozzle) & 228 \\
\hline Case S & 93 & 228 \\
\hline
\end{tabular}

Table 4 Numerical methods and boundary setting

\begin{tabular}{|c|c|c|}
\hline \multicolumn{2}{|c|}{ Calculation type } & Transient \\
\hline \multicolumn{2}{|c|}{ Rotor stator interface } & Transient Rotor Stator \\
\hline \multirow{2}{*}{ Inlet } & Water & Normal speed \\
\cline { 2 - 3 } & Air & $0 \mathrm{~m} / \mathrm{s}$ \\
\hline \multirow{2}{*}{ Outlet } & Water & Normal speed \\
\cline { 2 - 3 } & Air & $0 \mathrm{~m} / \mathrm{s}$ \\
\hline \multicolumn{2}{|c|}{ Upper of domain } & Opening \\
\hline \multicolumn{2}{|c|}{ Wall } & No slip wall \\
\hline
\end{tabular}

\section{Results and Discussion}

\subsection{Performance curves}

For this very low head cross flow turbine, the efficiency is calculated based on the potential energy difference between the upstream and downstream locations of the turbine model by the following equation:

$$
\eta=\frac{T \omega}{\rho g H Q}
$$

where $\eta$ is the efficiency of the turbine; $T$ is the output torque; $\omega$ is the angular velocity; $H$ is the water level difference between the upstream and downstream locations of the turbine model; and $Q$ is the water flow passing through the draft tube. 


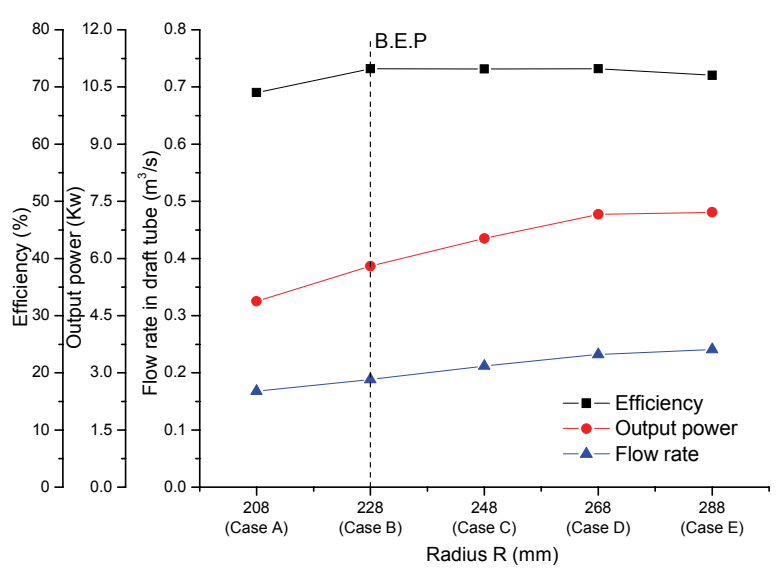

Fig. 4 Performance curves by turbine guide nozzle radius $R$

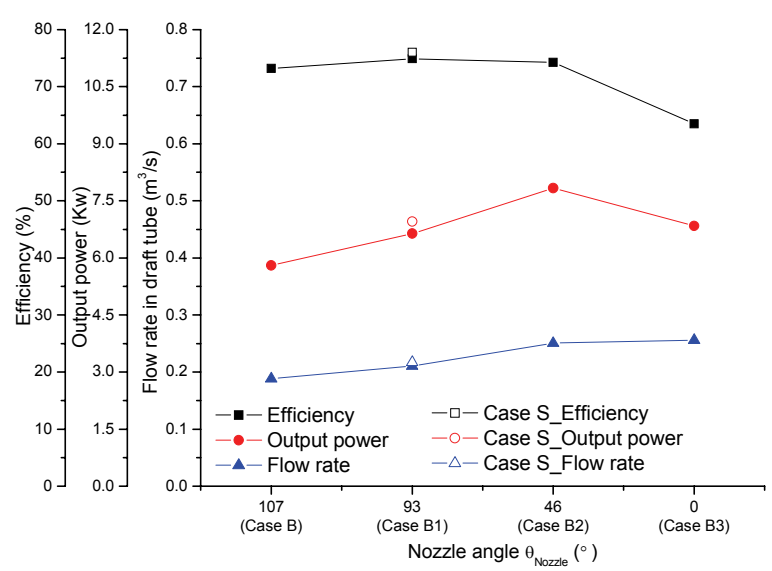

Fig. 5 Performance curves by turbine nozzle angle ONozzle

Figures 4 and 5 show the performance curves by the turbine guide nozzle radius and nozzle angle $\theta_{\text {Nozzle, }}$ respectively. Larger guide nozzle radius is good for guiding the flow into the draft tube, and contributes to generating more output power. The efficiency of the turbine reaches maximum at Case $B$ for which the radius of guide nozzle is $R=228 \mathrm{~mm}$. From Fig. 5 , it is inferred that the flow rate in the draft tube increases with shortening of the guide nozzle length. Especially for Case B3 without nozzle, the flow rate in draft tube is the maximum in comparison with the series of cases for different nozzle angle. The maximum efficiency reaches at Case B1 with $93^{\circ}$ nozzle angle. The efficiency reduces rapidly without guide nozzle. Comparing Case B1 and Case S, the guide nozzle with smooth inlet shape (Case S) further improves the efficiency of the turbine.

\subsection{Output power distribution}

In order to investigate the output power of the very low head cross flow turbine with open duct, the output power on the circumferential is divided into four regions and getting the local output power ratio as shown in Figs 6 and 7. The values of output power at every region are divided by the maximum one.

Figure 6 shows the local output power ratio at each region by guide nozzle radius $(R)$. The Case $\mathrm{E}$ has the maximum output power, which means the output power ratio of Case $\mathrm{E}$ is 1 as shown in Fig. 6. The larger the guide nozzle radius $(R)$, the more flow rate is sucked into the draft tube through the runner passage. It can be also observed that the influence of increasing the guide nozzle radius $(R)$ obviously rises to output power at Stages 1 and 2. However, the influence on the Regions 1 and 2 is poor, where loss of torque occurs.

Figure 7 presents the local output power ratio at each region by nozzle angle $\theta_{\text {Nozzle }}$. From Cases B to B3, with the nozzle angle $\left(\theta_{\text {Nozzle }}\right)$ reducing, the output power at Stages 1 and 2 increases. The total output power reaches the maximum one at Case B2. However, for Case B3 without guide nozzle, the output power at Stage 1 reduces, while that at Stage 2 rises. Moreover, the negative torque rise rapidly at Regions 1 and 2 , so the torque loss increases more in the case without guide nozzle at these two regions. The guide nozzle suppress the negative torque at Regions 1 and 2 effectively. Nevertheless, the efficiency and output power reduces if the nozzle length is too long.

In order to examine the influence factors for the performance variation of the cross flow turbine models in detail, internal flow is investigated.

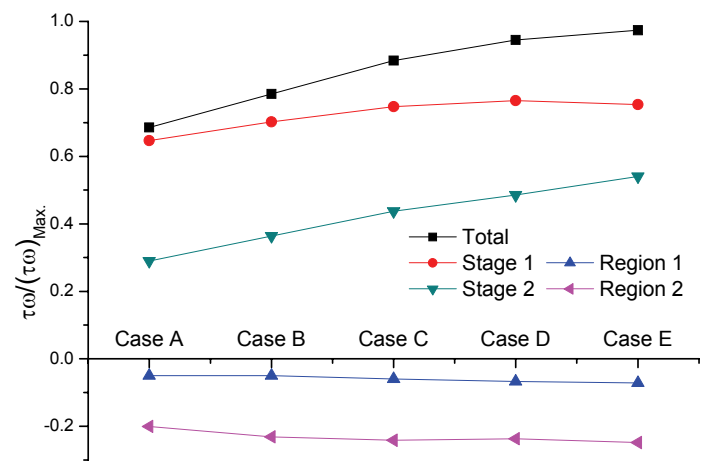

Fig. 6 Averaged local output power ratio at each region by guide nozzle radius $(R)$ 


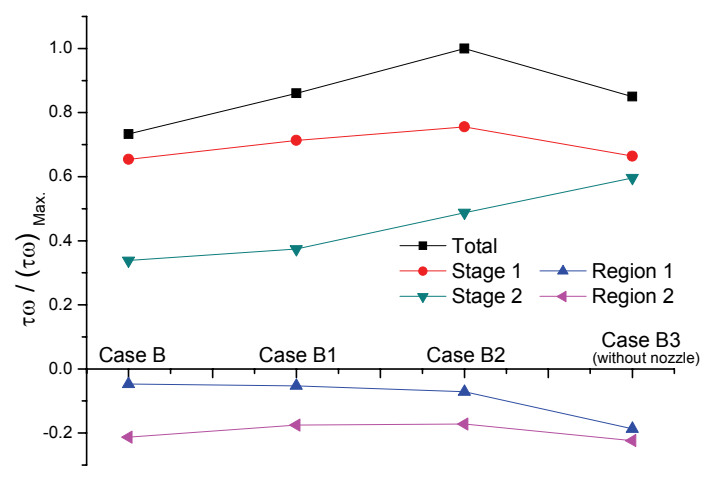

Fig. 7 Averaged local output power ratio at each region by nozzle angle ( $\left.\theta_{\text {Nozzle }}\right)$

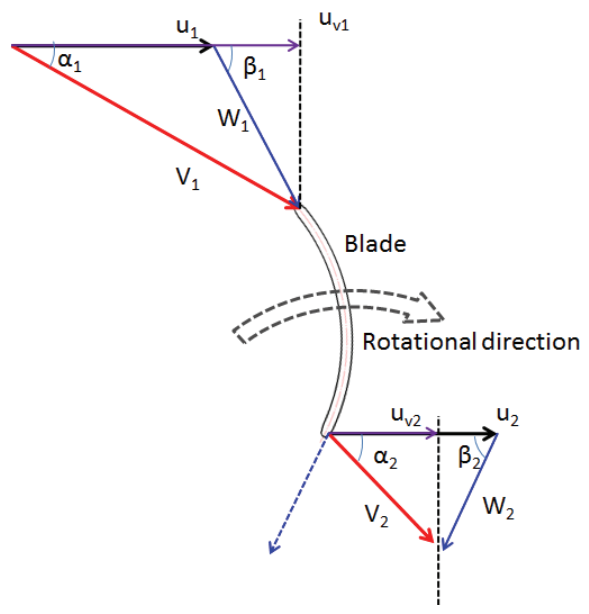

Fig. 8 Schematic of velocity triangle at blade entry and exit

\subsection{Velocity triangle components distribution}

For turbomachinery, the velocity triangle distribution on the entrance and exit of the blades is a very important factor on the performance[12]. The velocity triangle components on the turbine runner blades entry and exit are plotted to investigate the influence of guide nozzle on the performance. Figure 8 shows the schematic of velocity triangle at blade entry and exit. $a$ is the absolute angle that is between absolute $\operatorname{velocity}(V)$ and tip rotational $\operatorname{speed}(u), \quad \beta$ is the relative angle that is between relative velocity $(w)$ and tip rotational velocity $(u) . \beta_{1}$ is the inlet angle of blade. For maximum efficiency point, the relative angle $(\beta)$ should be close to the inlet angle of blade $\left(\beta_{1}\right)$, and the absolute angle $(a)$ of outflow at Stage 2 should be close to $90^{\circ}[13]$

Figure 9 shows the relative angle $(\beta)$ distribution at the runner blade passage inlet periphery of Stage 1 by guide nozzle radius $(R)$. The dashed line in the figure is the inlet angle of blade $\beta_{I}=33^{\circ}$. There are larger variations on the $\beta$ along with the circumferential location because of the blade. The $\beta$ on the runner passage part at Stage 1 shows that Case B is the one closest to $\beta_{1}$, which means Case $\mathrm{B}$ has the least energy loss by flow through the runner passage at Stage 1. A larger guide nozzle radius causes higher $\beta$, likewise, a smaller guide nozzle radius causes lower $\beta$, when compared to $\beta_{1}$. Guide nozzle radius gives significant effect on the relative angle at the entry of Stage 1 .

Figure 10 shows the relative angle $(\beta)$ distribution at the runner blade passage inlet periphery of Stage 1 by nozzle angle $\left(\theta_{\text {Nozzle }}\right)$. An appropriate nozzle angle for the guide nozzle plays an important role on the relatively angle( $\beta$ ). From Fig. 10, the $\beta$ of Case B1 is closer to $\beta_{1}$ than that of Case $\mathrm{B}$, and with the nozzle angle $\left(\theta_{\text {Nozzle }}\right)$ more shortened, the $\beta$ is farther away $\beta_{1}$. That's why the efficiency curve shows that Case B1 has the maximum one(See in Fig. 5).

Figures 11 and 12 shows the absolute angle( $a)$ distribution at the runner blade passage outlet periphery of Stage 2 by guide nozzle radius $(R)$ and nozzle angle $\left(\theta_{\text {Nozzle }}\right)$, respectively. The absolute angle (a) shows that the smaller guide nozzle radius and larger guide nozzle shape are better for the absolute angle being nearer to $90^{\circ}$ at the outlet of Stage 2 . The turbine generates most of its output power from circumferential location of $180^{\circ}$ to $220^{\circ}$.

An appropriate guide nozzle radius and nozzle angle plays an important role on the velocity triangle distribution. By increasing the guide nozzle radius and shortening the guide nozzle shape results in an

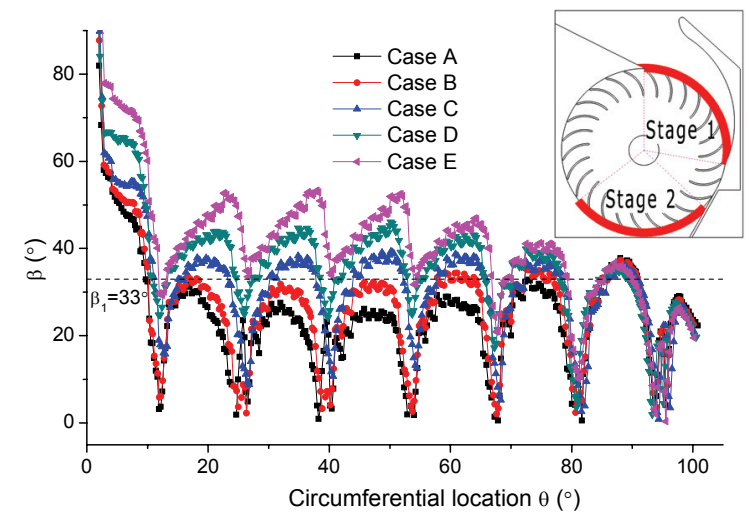

Fig. 9 The relative angle $(\beta)$ distribution at periphery of Stage 1 by guide nozzle radius $(R)$ 


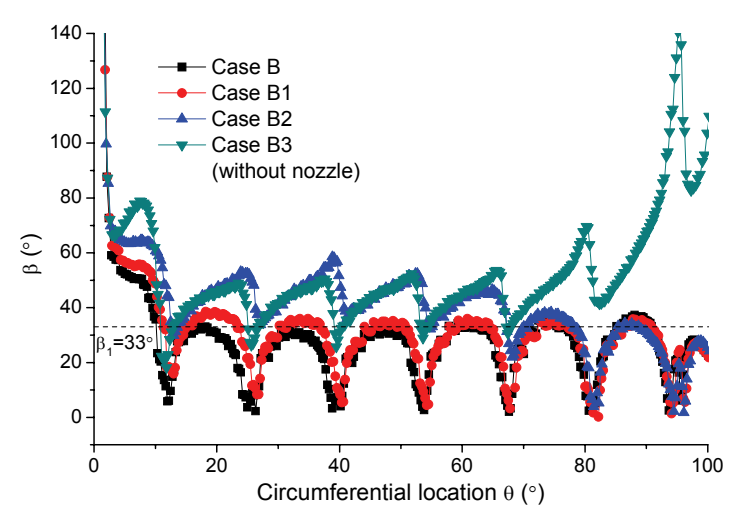

Fig. 10 The relative angle( $\beta)$ distribution at periphery of Stage 1 by nozzle angle (ONozzle

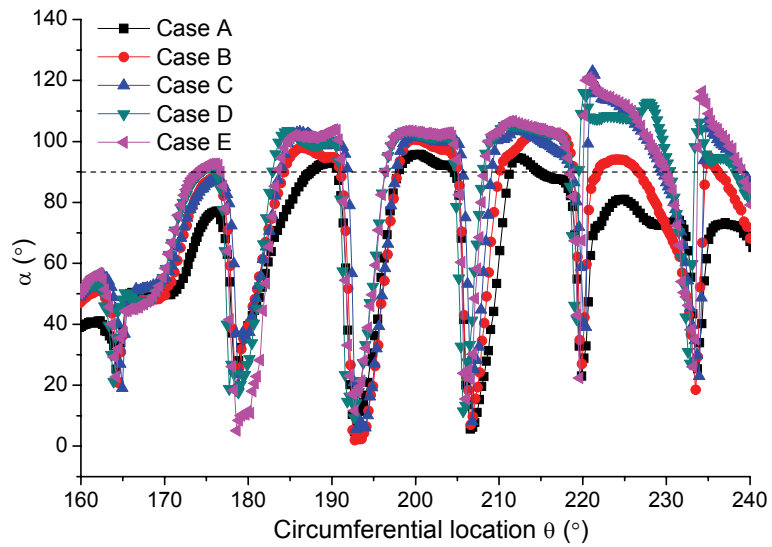

Fig. 11 The absolute angle(a) distribution at periphery of Stage 2 by guide nozzle radius $(R)$

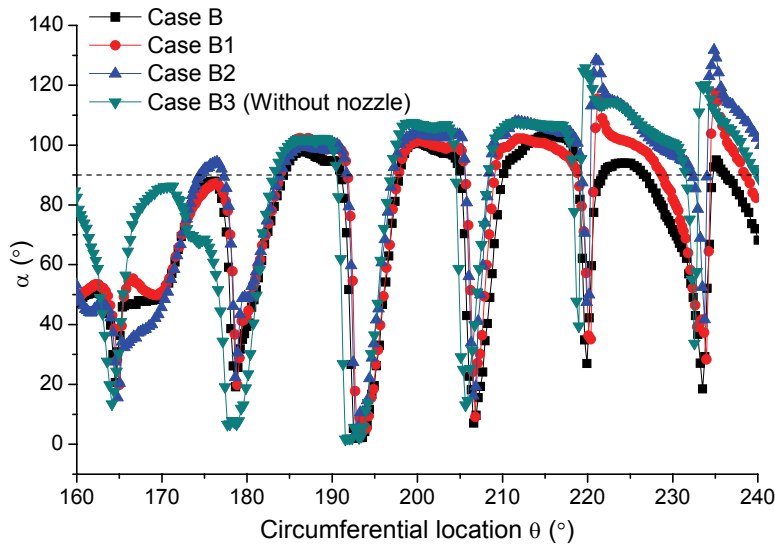

Fig. 12 The absolute angle(a) distribution at periphery of Stage 2 by nozzle angle (O№zzle

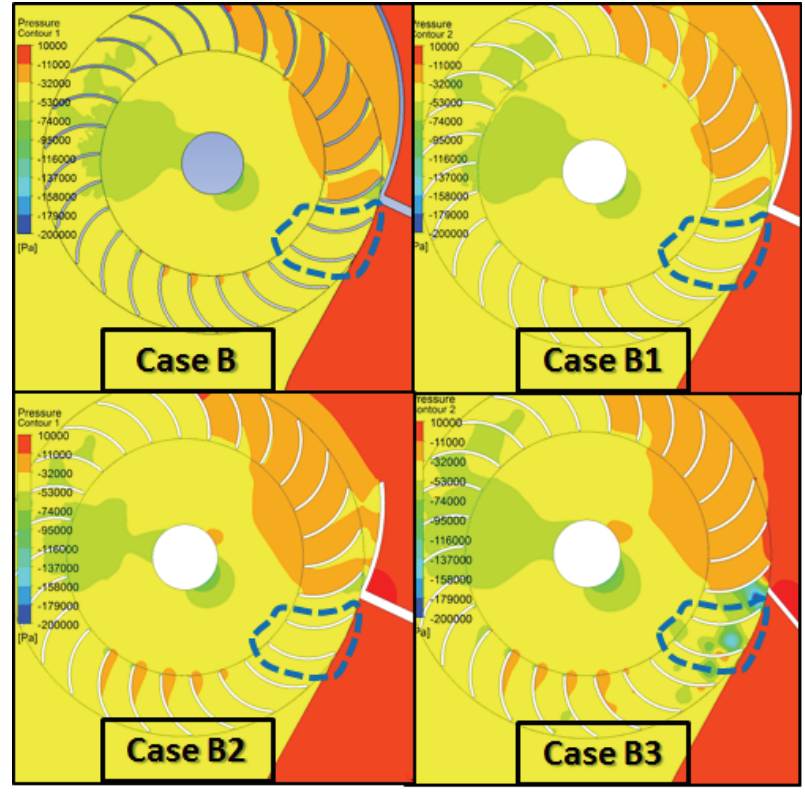

Fig. 13 Pressure contours

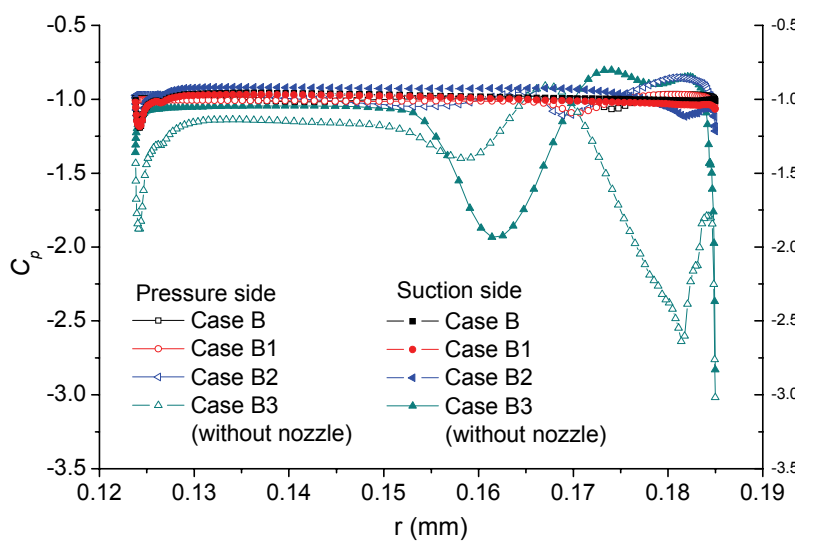

Fig. 14 Pressure distribution on the local blade surface

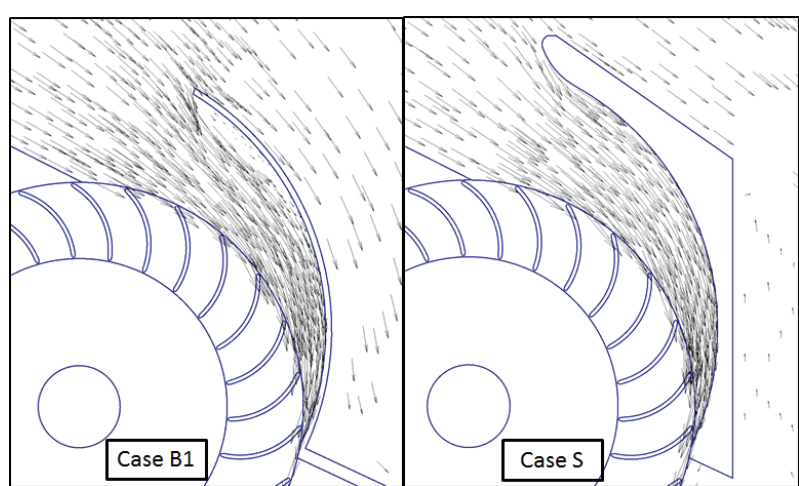

Fig. 15 Velocity vector at the nozzle passage 


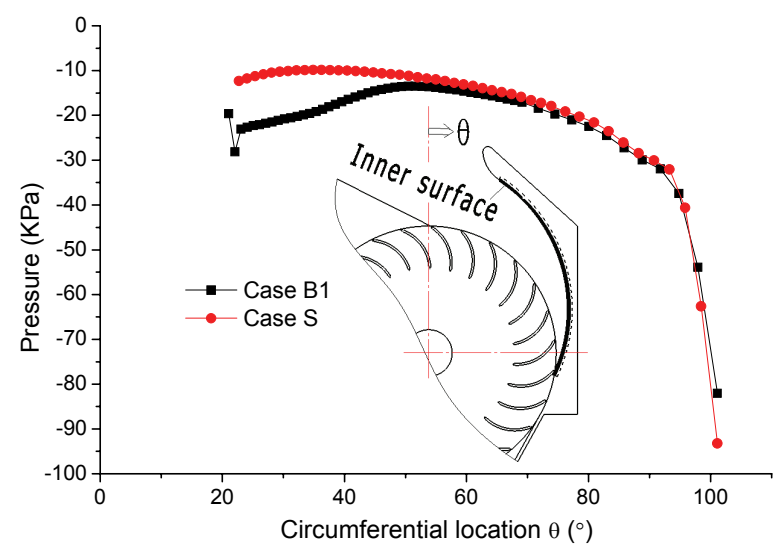

Fig. 16 Pressure distribution on the inner surface of guide nozzle

increased relative angle at Stage 1, however, the absolute angle at Stage 2 moves slightly farther away from $90^{\circ}$.

\subsection{Effect of turbine guide nozzle}

The effect of the guide nozzle on the turbine performance by the nozzle installation is investigated. From Figs. 5 and 7, it can been seen that for the turbine without guide nozzle, the efficiency and output power drop rapidly and also the negative torque rises considerably at Region 1 . The pressure contours around the runner are examined as shown in Fig. 13. It can be observed that larger pressure difference at Region 1 of Case B3, but with guide nozzle (Cases B, B1 and B2) the pressure difference relatively distributes evenly. In order to investigate the guide nozzle effect, the averaged pressure distribution on the local blade surface at Region 1 are plotted quantitatively as shown in Fig. 14. The pressure is averaged from two blades surface pressures at Region 1 (Fig. 13), and normalized to $C_{p}$ as in the following equation:

$$
C_{p}=\frac{p}{\rho g H}
$$

where $p$ is the averaged pressure on two blades surface at Region 1. The pressure around the blade shows the pressure of suction side is larger than that of pressure side, which means the torque generated by pressure difference is negative. This figure also shows the drastic change in pressure difference between the cases with and without nozzle. Cases B to B2 show similar pressure difference. It is conjectured that this change affects the torque value at Region 1.

\subsection{Effect of guide nozzle inlet shape}

Only the inlet shape of guide nozzle is different between Cases B1 and S. Fig. 15 shows the velocity vector at the nozzle passage for both at Cases B1 and $\mathrm{S}$. There is a region of flow separation flow near the inlet of the guide nozzle in Case B1. However, the separation flow disappears in Case $\mathrm{S}$ with smooth shape of guide nozzle inlet. The pressure distribution on the inner surface of the guide nozzle is plotted for Cases B1 and B as shown in Fig. 16. It can been seen that the pressure of Case $\mathrm{S}$ on the inner surface of guide nozzle changes gradually. However, for the Case B1, there are large variations of pressure at the inlet of guide nozzle, and the pressure values of these two cases remains same after the circumferential location of about $45^{\circ}$. It is conjectured that the separation flow at the guide nozzle inlet causes the decrease of flow rate, and leads to a drop of efficiency as shown in Fig. 5 .

\section{Conclusions}

This study presents the guide nozzle shape optimization of a very low head cross flow turbine with open ducted inlet channel, and also presents the performance and internal flow improvement by the installation of guide nozzle. There is $12.5 \%$ of efficiency improvement by attaching the guide nozzle on the turbine inlet, and the maximum efficiency is achieved as $76.04 \%$.

An appropriate guide nozzle radius and nozzle angle play an important role on the relative angle that should be close to the inlet angle of blade. However, the influence of guide nozzle on the absolute angle at outlet of Stage 2 is poor. Moreover, the guide nozzle of turbine plays a role of suppressing the negative torque at Region 1 by reducing the pressure difference on the blades.

Modifying the guide nozzle inlet part to a more smooth shape is better for guiding the water flow into the nozzle passage. The separation flow region at the guide nozzle inlet in Case B1 disappears when the 
guide nozzle shape is changed to Case $\mathrm{S}$, which has relatively smooth inlet shape.

\section{Acknowledgement}

본 논문은 2014학년도 목포대학교 연구소 활성화 지원비 지원에 의하여 연구되었음

\section{References}

(1) E.F. Lindsley, "Water power for your home," Popular Science, Vol. 210, No. 5, 1997.

(2) Kokubu, K., Kanemoto, T., Son, S. W. and Choi, Y. D., 2012, "Performance Improvement of a Micro Eco Cross-Flow Hydro Turbine," J. of the Korean Society of Marine Engineer, Vol. 36, No. 7, pp. 902 909.

(3) Kokubu, K., Yamasaki, K., Honda, H. and Kanemoto, T., "Effect of Inner Guide on Performances of Cross Flow Turbine," 26th IAHR Symposium on Hydraulic Machinery and Systems, doi:10.1088/1755-1315/15/4/042035.

(4) Kokubu, K., Son, S. W., Kanemoto, T. and Choi, Y. D., 2011, "Internal Flow Analysis on a Micro Cross-Flow Type Hydro Turbine at Very Low Specific Speed Range," Proceedings of the 11th Asian International Conference on Fluid Machinery, No. 195.

(5) Croquer. S. D., Andrade, J. D., Clarembaux, J., Jeanty, F. and Asuaje, M., 2012, "Numerical Investigation of a Banki Turbine in transient satate reaction ratio determination," Proceeding of ASME Turbo Expo 2012, GT2012 68809.

(6) Croquer. S. D., Andrade, J. D., Clarembaux, J., Jeanty, F. and Asuaje, M., 2012, Use of CFD Tools in Internal Deflector Design for Cross Flow Turbine Efficiency Improvement," Proceeding of the ASME 2012 Fluids Engineering Summer Meeting, FEDSM2012 72017.

(7) Hayati, O., "Effect of Interior Guide Tubes in Cross Flow Turbine Runner on Turbine Performance," Int. J. Energy Res. 2000: 24: 953 964.

(8) Chen, Z. M. and Choi, Y. D., "Performance and Internal Flow Characteristics of a Cross Flow Turbine by Guide Vane Angle," IOP Conf. Ser.: Mater. Sci. Eng. 52052031.

(9) Choi, Y. D., Yoon, H. Y., Inagaki, M., Ooike, S., Kim, Y. J. and Lee, Y. H., 2010, "Performance Improvement of a Cross-Flow Hydro Turbine by Air Layer Effect," J. of Fluid Machinery, Vol. 13 No. 4, pp. 37 44.

(10) Wu, J., Shimmei, K., Tani, K., Niikura, K. and Sato, J., 2007, "CFD-Based Design Optimization for Hydro Turbines," J. of Fluids Engineering, Vol. 129, pp. 159 168.

(11) ANSYS Inc., "ANSYS CFX Documentation," ver. 12, http://www.ansys.com, 2012.

(12) Ingram, G., 2009, Basic Concepts in turbomachinery, Bookboon.

(13) Mockmore, C. A., Merryfield, F., 1949, "The Banki Water Turbine, In Bullettin Series," Engineering Experiment Station; Oregon State System of Higher Education, Oregon State College: Corvallis.USA 